\title{
EDUCAÇÃO TÉCNICA E ENGENHARIA NO PENSAMENTO DO GENERAL EDMUNDO DE MACEDO SOARES
}

\author{
Technic education and engineering in the \\ general macedo soares' thought
}

Alexandre de Sá Avelar*

\section{Resumo}

O presente artigo pretende oferecer uma contribuição para o estudo do papel desempenhado pela educação técnica e pela engenharia no processo de modernização brasileira, aqui identificada com a expansão capitalista iniciada nos anos 1930 e impulsionada pela indústria. Partese do pressuposto teórico de que esta modernização não envolveu apenas transformações na base material da sociedade, mas também a produção de discursos que procuravam legitimar a hegemonia - em construção - da fração industrial da burguesia brasileira. Desta forma, ganha importância a ação dos chamados intelectuais orgânicos, homens responsáveis pela coesão moral e intelectual da classe dominante. A discussão destes dois temas fundamentais para a hegemonia da burguesia no Brasil - a educação técnica e a engenharia - será abordada sob o ponto de vista de um dos seus mais expressivos intelectuais, o general Edmundo de Macedo Soares.

Palavras-chave: Edmundo de Macedo Soares. Modernização brasileira. Educação técnica. Engenharia.

* Mestre em História pela Universidade Estadual do Rio de Janeiro; doutor em História pela Universidade Federal Fluminense. Email: alexandre.avelar@uol.com.br 


\section{Abstract}

This article intends to offer a contribution for the study of the role performed by technical education and the engineering in the brazilian process of modernization, identified here with the capitalist expansion started in the 1930's and driven by industry. It starts from the theoretical presupposition that the modernization has not involved only transformations in the material basis of society, but also a production of discourses which intended to legitimate the hegemony of the industrial fraction of brazilian bourgeois has had - in construction. In this way, the action made by the ones called organic intellectuals, men responsible for the moral and intellectual cohesion in dominant class, became important. The discussion about these two themes - the technical education and engineering -, which are seminal for the bourgeois hegemony in Brazil, will be approached under the point of view of its most expressive intellectuals', the general Edmundo de Macedo Soares

Keywords: Edmundo de Macedo Soares. Brazilian modernization. Technical education. Engineering.

\section{INTRODUÇÃO: A IDÉIA DE MODERNIZAÇÃO BRASILEIRA}

Poucas idéias são tão recorrentes na história republicana do Brasil quanto aquelas vinculadas à modernização. Em diversas épocas, sucessivas gerações de intelectuais se preocuparam em diagnosticar o que era o atraso na sociedade brasileira e as fórmulas de sua superação. Para os "ilustrados" do final do Império, a economia escravista e as sobrevivências do passado colonial eram os sinais mais evidentes do longo caminho a percorrer até que o país atingisse os níveis de desenvolvimento experimentados pelas nações de capitalismo avançado. Claramente marcados pelo "bando de novas idéias", de que falava Sylvio Romero, esses homens depositavam suas mais profundas expectativas no avanço do conhecimento científico. As doutrinas que professavam tinham como ponto em comum fornecer supostas bases para uma ação esclarecida sobre a realidade que, por qualquer ótica, demonstrava os visíveis sinais do nosso arcaísmo reinante. ${ }^{1}$ 
Os fracassos dos governos militares que inauguraram o regime republicano pareceram jogar por terra essas expectativas modernizantes. Reafirmou-se o poder das oligarquias regionais, ancoradas na "vocação agrária do Brasil" e num liberalismo federalista excludente, enquanto se processava uma completa reorganização do poder político sob a égide da "política dos governadores" e da "política do café com leite". Os lucros cada vez maiores auferidos com as exportações de café completavam um quadro em que as bases da dominação do capital mercantil-agrário pareciam inteiramente sólidas.

Essa solidez deu os primeiros sinais de que se desmancharia no ar com a I Guerra Mundial. Nesta ocasião, as fragilidades de uma economia essencialmente agrária foram mostradas a nu. Estava em jogo uma reordenação do poder mundial, na qual as novas modalidades de conflito se relacionavam à capacidade da indústria nacional, o que deixava países como o Brasil em uma situação ameaçadora. Houve um inevitável avanço da industrialização que resultou ainda numa expressiva mobilização da mãode-obra proletária. Esta, por sua vez, influenciada pelas idéias anarquistas e pelos reflexos da Revolução de Outubro, mostrava-se ameaçadora aos grupos dominantes. Acirraram-se as críticas aos desmandos dos grupos oligárquicos e importantes crises políticas se sucederam nos anos 20. Neste cenário, forjaram-se novas propostas de modernização e projetos de intervenção social.

Havia certamente novas idéias no horizonte da intelectualidade dos anos 20 e 30 . Não há dúvidas de que o integralismo e o comunismo ofereciam, sob perspectivas distintas, respostas aos desafios impostos pela crise da dominação oligárquica. Eram, também, neste sentido, projetos de modernização. Estes, contudo, não foram hegemônicos, e suas poucas vitórias foram precárias e efêmeras. Interessava aqui um certo projeto de modernização que combinava elementos de avanço com compromissos com a velha ordem oligárquica, sendo certamente 0 reflexo de uma séria crise de hegemonia que já se desenhava nos anos 20 e que ganhou contornos claros na década de 30. Sem aniquilar o latifúndio e a produção agrária exportadora, esse projeto de modernização redefiniu as bases da acumulação capitalista no Brasil a partir do peso cada vez maior conferido 
ao setor industrial. Comportou ainda a utilização de certas premissas do ideário cientificista que atravessou o final do II Reinado, retomando noções advindas do positivismo, do evolucionismo e do naturalismo. Tudo isso regido por uma elite dirigente, educada sob moldes técnicos e que devia promover as transformações que o "Brasil real" reclamava.

Também este projeto teve seus intelectuais legitimadores, homens produtores de um discurso tendente ao consenso e que visava a transformar em interesses nacionais os interesses das classes ou frações de classe beneficiadas com a modernização em curso. Eram, neste sentido, intelectuais orgânicos. O engenheiro militar Edmundo de Macedo Soares e Silva era um destes homens.

A noção de intelectual orgânico remonta ao pensador marxista italiano Antonio Gramsci e aponta para a existência de uma certa direção moral exercida que se manifesta no campo superestrutural. A homogeneidade da classe que representa e a unificação de seus interesses são funções primordiais deste tipo de intelectual. Essas funções podem sublinhar perspectivas transformadoras e/ou conservadores da ordem vigente. $\mathrm{O}$ intelectual orgânico é, dessa forma, dotado de uma formação especializada em determinada área de atuação essencial para a conquista ( ação transformadora ) e manutenção ( ação conservadora ) do papel dirigente de determinada classe social e destina-se, ainda, a realizar atividades intelectuais correspondentes a essa classe. ${ }^{2}$

$\mathrm{Na}$ complexa trama histórica da modernização brasileira, é possível apontar, para os engenheiros ligados aos complexos urbano-industriais, a função de intelectuais orgânicos. Não apenas favoreceram e impulsionaram o crescimento das atividades voltadas para o mercado interno, como foram importantes para assegurar, sob novas bases, a reprodução da lógica autoritária do capitalismo brasileiro, mormente no que se refere aos mecanismos de controle da mão-de-obra. A adaptação da força de trabalho aos imperativos da acumulação de capital revela o caráter dirigente da atuação da engenharia. Partilhando com os representantes da burguesia industrial dos mesmos ideais de progresso e de crença no papel preponderante da ciência como fator de desenvolvimento da produção, os engenheiros tornaram-se peças importantes na difusão da base econômica e da superestrutura ideológica que caracterizavam o mundo burguês. ${ }^{3}$ 
Convém ressaltar que a modernização brasileira é aqui pensada como um conjunto sistêmico de transformações tangíveis na estrutura produtiva, bem como um campo de conflitos pela construção de projetos e discursos hegemônicos. Neste sentido, a história torna-se um "campo de lutas pelas práticas, questões e reflexões colocadas pelos e a partir dos sujeitos sociais". ${ }^{4}$ Potencializa-se, dessa maneira, uma dimensão simbólica que permite enxergar a modernização brasileira para além de suas manifestações materiais, considerando os conflitos entre as diversas classes e frações de classe para que suas visões de mundo fossem progressivamente estendidas para todos os segmentos da sociedade. Ou, como aponta Luis Werneck Vianna, a modernização autoritária brasileira se deu num campo "em que os atores sociais disputam qual deles é o mais moderno e merecedor, portanto, da confiança de todos para dirigir a sociedade" ${ }^{5}$ Pensar a história como um campo de múltiplas experiências e conflitos envolvendo disputas entre diversos interesses e visões de mundo implica admitir que ação e discurso constituem práticas reais de intervenção social e que, segundo Fábio Maza, devem ser tomados como "ação concreta que visavam a convencer pessoas, dissimular contradições, plasmar idéias ou impor projetos e versões como as únicas possíveis". ${ }^{\circ}$

\section{Macedo Soares: tecnologia, engenharia e industrialização na modernização brasileira}

A modernização brasileira, ao confundir-se com a racionalização que acompanhava a atividade econômica capitalista é, ao mesmo tempo, uma modernização científica e tecnológica. Os padrões instrumentais desta ratio penetraram em diversos outros domínios do social, configurando uma totalidade destruidora das formas pretéritas de organização social. Como afirma Habermas, "na medida em que a técnica e a ciência penetram os setores institucionais da sociedade, transformando (...) as próprias instituições, as antigas legitimações se desmontam". ${ }^{7}$

Prosseguindo suas reflexões sobre o papel da técnica e da ciência como elementos estruturantes da modernização capitalista, Habermas aponta para as práticas autoritárias procedentes da incorporação destes dois novos domínios - técnica e ciência - ao mundo da produção social. 
Como o que está em jogo é a escolha correta entre as estratégias e o emprego adequado das tecnologias e dos conhecimentos científicos, essa racionalidade demandava um grupo dirigente apto a conduzi-la, adaptando todo o conjunto de relações sociais aos seus desígnios. Portador de um saber socialmente reconhecido como capaz de intervir cientificamente na sociedade, este grupo reforça os laços de dominação e reprodução do capital. $^{8}$

A reflexão sobre a tecnologia, de acordo com Fábio Maza, deve estar articulada aos seus pressupostos sociais. ${ }^{9}$ Isso significa ainda considerá-la como um momento das forças de produção e, portanto, sem exterioridade em relação ao sistema econômico. Sob essa ótica, evita-se o risco de tratar o "fato técnico" como totalmente desvinculado do "fato social" ${ }^{10}$ Contra a falsa pretensão de objetividade intrínseca da tecnologia, Lukács afirmava, em polêmica com Bakunin, seu caráter de fenômeno social, abarcando um leque variado de relações sociais, fatores culturais e físicos, pois "a técnica é uma parte, um momento naturalmente de grande importância das forças produtivas sociais, mas não é, simplesmente, idêntica a elas (...) nem o momento final ou absoluto das mudanças dessas forças". ${ }^{11}$

Ao mesmo tempo em que era forçoso reconhecer a técnica como um fenômeno constitutivo de um universo simbólico-cultural, funcionando como "um aprendizado baseado na experiência sensível em ensinamentos transmitidos de geração em geração ou transcritos em tratados” 12 , deviase considerar a tecnologia como distintiva da época moderna, significando "a solução de problemas técnicos por meio de teorias, métodos e processos científicos". ${ }^{13}$ Assim,

(...) a tecnologia, (...) simbiose da técnica com a ciência moderna, constituiria também um conjunto de atividades humanas, associadas a um sistema de símbolos, instrumentos e máquinas, visando à construção de obras e fabricação de produtos segundo teorias, métodos e processos da ciência moderna. ${ }^{14}$

Própria da paisagem totalizante que a modernidade capitalista impunha, a tecnologia surgia englobando o universo mental do homem, pois 
ela se inseria num "sistema de símbolos", representando, portanto, uma categoria cultural. Por outro lado, a tecnologia era também um elemento material, a aplicação racional da ciência à resolução dos problemas relacionados à produção capitalista. Este último aspecto supunha a manipulação e controle de processos materiais que desembocavam no exercício de funções altamente especializadas. Será visto ao longo deste artigo como os engenheiros se qualificaram como os portadores dos atributos necessários para se tornarem os manipuladores da tecnologia no mundo moderno.

Tanto nos países do núcleo central quanto naqueles situados na zona periférica do capitalismo, as transformações científico-tecnológicas ocorridas a partir da segunda metade do século XIX repercutiram fortemente na função social do engenheiro como um organizador da produção e portador de saberes cientificamente legitimados para a intervenção na realidade social. A euforia burguesa provocada pela aceleração da produção e pelos crescentes empreendimentos industriais teve no conhecimento científico um dos seus pilares. Poucos duvidavam da capacidade da ciência em promover melhores condições materiais de existência para parcelas cada vez maiores da população. A engenharia tornava-se, a partir de então, um campo privilegiado de ação, posto que era vista como o exemplo mais efetivo da aplicação benfeitora da acumulação do pensamento científico. Evidenciavase, portanto, a produção de um status para o engenheiro, considerado dirigente e responsável pala aplicação da tecnologia à produção. De acordo com Lili K. Kawamura:

A categoria profissional do engenheiro no capitalismo consiste em determinada parcela social com qualificação técnico-científica, especialmente voltada para as atividades de utilização da ciência no processo produtivo. Tal qualificação tem-Ihe sido historicamente outorgada de modo sistemático pelo aparelho escolar, em nível de ensino superior. $A$ atuação do engenheiro como legitimador da autoridade do capital sobre a força de trabalho era assegurada também pelos mecanismos de acesso à formação escolar profissional. Os cursos de engenharia exigiam conhecimentos de ciências 
básicas, conclusão de escolas de nível médio e período integral de estudos. Essas determinações funcionavam evidentemente como um meio de seleção e restrição ao ingresso na carreira, uma vez que grande parcela dos jovens não atendia às exigências citadas. Excluindo, portanto, significativa parcela populacional, o ensino de engenharia evidenciava uma função social importante nas condições de reprodução do capitalismo industrial. Aos marginalizados, cabiam funções consideradas inferiores e destituídas de poder de mando, enquanto os engenheiros reservavam a si mesmos o controle de saberes específicos, destinados a oferecer soluções para os problemas técnicos produzidos pela sociedade. ${ }^{15}$

$\mathrm{Na}$ dinâmica de reprodução do capital sob as vestes de uma modernização autoritário-conservadora, os engenheiros assumiam 0 papel de intelectuais orgânicos de uma burguesia industrial, que buscava consolidar sua hegemonia realizando concessões pontuais à classe operária, ao mesmo tempo em que mantinha os esquemas mais rígidos de controle social. A dominação sóciometabólica do capital ${ }^{16}$ impunha não apenas a produção de mercadorias em larga escala, mas a produção de um consenso pretensamente natural, que legitimasse a coerção que envolvia a reprodução das relações sociais capitalistas. Em uma passagem de O Capital, Marx discute o caráter duplo da dominação do capital, o estritamente econômico e aquele relacionado ao controle da mão-de-obra:

Antes de tudo, o motivo que impele e o motivo que determina o processo de produção capitalista é a maior expansão possível do próprio capital, isto é, a maior produção possível de mais-valia, portanto, a maior exploração possível da força de trabalho. Com a quantidade de trabalhadores simultaneamente empregados, cresce sua resistência, e com ela, necessariamente, a pressão do capital para dominar essa resistência. A direção exercida pelo capitalista não é apenas uma função especial, derivada da natureza do processo de trabalho social e peculiar a esse processo; além disso, ela se 
destina a explorar um processo de trabalho social, e por isso, tem por condição o antagonismo inevitável entre o explorador e a matéria-prima de sua exploração. Com o volume de meios de produção que se põe diante do trabalhador como propriedade alheia, cresce a necessidade de se controlar adequadamente a aplicação desses meios. Além disso, a cooperação dos assalariados é levada a efeito apenas pelo capital que os emprega simultaneamente. A conexão entre as funções que exercem e a unidade que forma o organismo produtivo está fora deles, no capital que os põe juntos e os mantém juntos. A conexão entre os seus trabalhos apareceIhes idealmente como plano, e praticamente como autoridade do capitalista, como o poder de uma vontade alheia que subordina a um objetivo próprio a ação dos assalariados. ${ }^{17}$

Todas estas questões envolvendo os problemas relacionados à educação técnica e à engenharia prolongaram-se durante todo o ciclo desenvolvimentista brasileiro, tendo sido objetos de reflexões de diversos economistas, historiadores, sociólogos, políticos e industriais. ${ }^{18}$ Por outro lado, raros foram os militares que se dedicaram a este debate, ainda que as Forças Armadas demonstrassem interesse na expansão industrial, sempre preocupadas com a situação bélica do País. A escolha de Macedo Soares, por seu turno, implica em considerá-lo como um ator relevante para este período desenvolvimentista, não apenas pela suas intervenções intelectuais, como também pela sua destacada atuação tanto no âmbito dos aparelhos estatais quanto em órgãos organicamente ligados aos interesses da burguesia nacional, como a Confederação Nacional da Indústria (CNI). Militar com formação em engenharia na França, Macedo Soares foi ativo nas lutas tenentistas nos anos 20 - o que lhe custou o exílio em terras francesas. Retornando ao Brasil pouco antes da derrubada do governo de Washington Luís, participou das conspirações que levaram Vargas ao poder. Em seguida, tomou parte nas seguidas comissões nomeadas pelo governo federal para o estudo do problema siderúrgico nacional, o que culminou com sua participação decisiva na montagem da Companhia Siderúrgica Nacional (CSN), verdadeiro marco da industrialização brasileira. Ocupou ainda os ministérios da Viação e da 
Indústria e Comércio, nos governos Dutra e Costa e Silva, e governou o Rio de Janeiro entre 1946 e 1950. Integrou a direção de diversas empresas, presidiu a CSN e a CNI e foi membro de outras várias associações classistas, como a Confederação Nacional do Comércio. Ao longo desta trajetória, produziu inúmeros artigos, aulas e conferências sobre diversos assuntos relacionados à expansão do capitalismo industrial no Brasil. Seu percurso de vida e intelectual nos permite compreender de que maneira o Estado e os interesses da fração industrial da burguesia brasileira se articulavam, definindo políticas públicas de "interesse nacional". A intenção, neste trabalho, "é estudar o caso de um ator individual [ e suas idéias ] que, em contexto histórico-social específico, conseguiu sintetizar preocupações e interesses de um grupo social e projetá-los no cenário político no momento em que as relações de força se mostraram favoráveis". ${ }^{19}$

Em seus trabalhos sobre o tema, Macedo Soares ampliou imensamente a atuação do engenheiro, elegendo-o como portador de uma verdadeira missão social, pois era o homem

Intermediário que, tendo base científica, absorve a tecnologia e a transmite simplificada, visando a uma utilização imediata, às diferentes camadas de trabalhadores. Estes, recebendo-a, adquirem condições de obter função social mais elevada, de melhor remuneração, além da possibilidade de progredir por aperfeiçoamento contínuo. ${ }^{20}$

As funções do engenheiro não estavam restritas, portanto, ao aperfeiçoamento técnico e à difusão científica. Ele atuava de forma importante na promoção de melhorias de vida para os próprios trabalhadores mediante a instrução que recebiam. Justificava-se aqui plenamente a ascendência do engenheiro sobre a mão-de-obra, uma vez que além de ser "um profissional que calcula, desenha e fabrica ou constrói, (...) é também gerente, educador e organizador que conduz as reformas sociais" ${ }^{21} \mathrm{Na}$ medida em que era naturalmente um benfeitor, não cabia por parte dos operários questionar a existência desta elite técnica e científica, pois "ela se formará sempre, por processo natural, independente de nossa vontade. Resulta de uma seleção inevitável”. ${ }^{22}$ 
No cumprimento de suas atribuições "técnicas" e "sociais", o engenheiro deveria desenvolver uma lista de habilidades imprescindíveis, exigindo-se dele, "além do saber acadêmico, inteligência inovadora, espírito de iniciativa e mentalidade criadora" ${ }^{23}$ Essas características eram reveladoras da concepção de liderança que norteava o universo de atuação deste profissional. A amplitude de seus canais de intervenção era mais uma prova de que a engenharia estava a serviço da sociedade e não de certos interesses particulares:

Dizer-se que o engenheiro está a serviço do capital é limitar o seu papel; ele está, de fato, a serviço da sociedade, e, portanto, dos governos que a conduzem dentro das normas dos regimes. Em conseqüência, está também à disposição das universidades em que ele desempenha papel de relevo no ensino e na formação ( na prancheta, nos laboratórios e nas oficinas ). Dá preparo ao estudante e treina o operário. ${ }^{24}$

A sólida formação científica destinada ao engenheiro conduzia-o à realização de grandes obras, cujos desenvolvimentos chegavam a escapar ao consciente deste profissional, dado o volume de trabalho a que se dedicava. Com efeito, a grande capacidade realizadora do engenheiro tornava-o apto mesmo a se envolver em outras profissões:

O engenheiro, de um lado, e do outro o cálculo, a prancheta e o relatório são inseparáveis. (...) Deve possuir técnica, imaginação e espírito criador. Dizia Buffon que 'o gênio é uma longa paciência'. Da mesma maneira, pode-se afirmar que a criação onde quer que ela se realize, deriva da superposição de uma série de conhecimentos e de uma multidão de pequenas descobertas que a imaginação proporciona. É o resultado de um trabalho paciente e longo. $\mathrm{O}$ engenheiro que cultiva a profissão pratica, sem suspeitar muitas vezes, esse método de trabalhar; assim, ao cabo de anos de exercício, ele começa a realizar obras magníficas que surgem do seu subconsciente, alimentado pelo saber acumulado. Por isso que o engenheiro tem todas essas faculdades, sua ação num país em desenvolvimento, como o Brasil, é da maior importância. Direi mesmo, fundamental. Ao passo que o engenheiro, com sua base, pode atirar-se à posse rápida dos elementos 
de outras profissões, raro é que suceda o inverso. Daí a predominância, no estudo das soluções racionais a dar aos problemas de um país em desenvolvimento, dos que cursaram Escolas como esta [ Faculdade de Engenharia da Universidade do Estado da Guanabara ].

Cumprindo as funções de promover o desenvolvimento econômico, de dirigir homens e empreendimentos, o engenheiro era um verdadeiro construtor da nação e, conseqüentemente, um dos responsáveis pela projeção externa do Brasil. Essa idéia transpareceu em uma aula inaugural de Macedo Soares no Instituto Tecnológico da Aeronáutica ( ITA ), na cidade de São José dos Campos-SP, quando afirmou que "num grupo humano como este, estão o presente e o futuro da Pátria. Vossa missão não é só engrandecer o Brasil, o que seria já extraordinário, mas é, sobretudo, torná-lo útil e respeitado no concerto internacional”. ${ }^{26}$

O papel desempenhado pela educação técnica no pensamento de Macedo Soares acompanha, obviamente, as considerações que nosso personagem realiza sobre a tecnologia. $\mathrm{O}$ que se percebe não é a técnica apenas como suporte da industrialização. Sobressai a percepção de uma visão de mundo, de uma organização cultural baseada no desenvolvimento pleno da tecnologia. Isto se revela nas seguintes indagações:

(...) é a antiga concepção da cultura compatível com essa predominância da técnica e não estará terminando, na história humana, a influência greco-latina, até agora decisiva, sobre a formação de nossas concepções européias? Estará para vir americana ou russo-chinesa, onde dominará agressivamente a técnica, dando-nos uma cultura de um tipo tão diferente que não reconheceremos mais nossa tradição anterior? ${ }^{27}$

A "agressividade" da técnica tinha um sentido bastante preciso para Macedo Soares: tratava-se de uma ruptura drástica com um modelo cultural do Ocidente, no qual os estudos humanísticos tinham predominância sobre aqueles mais dedicados a temas de tecnologia e ciência. Naquele estágio da corrida econômica mundial, os países que se voltassem prioritariamente para as letras ao invés da técnica estariam condenados ao eterno subdesenvolvimento. 
Toda a análise que Macedo Soares empreendeu sobre a educação e a formação técnica do brasileiro tinha como ponto de partida a constatação de que o ensino nacional deveria espelhar a realidade sócioeconômica. Nesse sentido, a partir da $2^{\text {a }}$ Guerra Mundial, era absolutamente impossível manter o bacharelismo que predominava nos aparelhos escolares brasileiros:

Os educadores brasileiros, após a Segunda Guerra Mundial, chegaram à conclusão de que o Brasil deveria alargar sua área de cultura. Não se tratava mais de se ensinar aos estudantes uma ou duas línguas mortas ( o grego e o latim ) para que eles pudessem ler os autores clássicos e penetrar-lhes as idéias. E, ao lado disso, ensinar rudimentos de ciências para permitir-Ihes a adoção de uma profissão liberal. (...) Saber não é só acumular conhecimento, mas ter base para chegar a conclusões, indagando as razões dos fatos para dominálos e conduzi-los. A educação precisava ser conduzida neste sentido, para que não se formassem apenas eruditos. Ensinar a experimentar, a pesquisar, é fundamental para que se possa saber e explicar o que se passa e, daí, reproduzir, como for mais conveniente ao uso, o que desejarmos. É toda uma filosofia da educação que não se adotava entre nós, senão por exceção e por pessoas com formação no estrangeiro. ${ }^{28}$

A deficiência da formação técnica do brasileiro se agravava ainda mais quando se considerava a escassa pesquisa científica e tecnológica no país, o que tornavam inviáveis os esforços mais profundos para 0 desenvolvimento econômico e social:

Há uma estrutura de serviços científicos e tecnológicos em todos os países que evolui e se aperfeiçoa, através dos tempos. Os dados obtidos por esses serviços e fornecidos a quem deles necessita são indispensáveis para o exercício de qualquer atividade industrial. Com efeito, os grandes empreendimentos industriais precisam recolher, para que se possam traduzir em realizações efetivas, uma série de 
informações importantíssimas sobre meteorologia, regime de rios, geologia de diferentes regiões, ensino, populações, etc. São elementos gerais de orientação sem os quais não se pode dar início rápido a nenhum projeto de vulto.

Nos países como o nosso, em fase de desenvolvimento, esses elementos são, quase sempre, escassos e algumas vezes inexistentes. Organizações públicas para obtê-los figuram nos organogramas ministeriais, mas os dados fornecidos são incompletos e não abrangem muitas regiões do país, ainda imperfeitamente estudadas.

(...) A formação de cientistas, como profissionais liberais, no mesmo nível das outras profissões, é relativamente recente. Hoje o cientista é um procurado pelos governos e grandes organizações industriais, do mesmo modo que um químico ou um engenheiro.

Os países pouco desenvolvidos estão ainda no limiar do preparo dos cientistas e tecnologistas que são indispensáveis para o seu progresso. A falta de pesquisa organizada se reflete no conhecimento precário dos recursos materiais próprios e projeta-se, igualmente, na ausência de padrões técnicos, ou normas, cuja adoção facilita o progresso industrial. ${ }^{29}$

Avaliando os avanços da industrialização brasileira nos últimos trinta anos, Macedo Soares acreditava que a mentalidade transformadora que a indústria provocava não havia ainda penetrado totalmente na população brasileira. Nesta ocasião - uma conferência na Escola Superior de Guerra, em 1961 - o engenheiro metalúrgico e militar concluía que nossa organização econômica ainda não contemplava todos os interesses do setor industrial: os sistemas fiscal e bancário eram ainda precários, o sistema de transporte não era eficiente e a legislação trabalhista sofria um processo de "desvirtuamento". Todas essas questões deveriam ser saneadas. Contudo, a autonomia econômica e industrial 
(...) só virá quando formos capazes de conceber, projetar e fabricar equipamentos, produzir ferramentas e dispositivos. E para isso necessitamos de especialistas. É o grande problema que só resolveremos dando ênfase ao ensino, orientando nossa mocidade para profissões ligadas à industrialização: mais escolas técnicas e menos ginásios. ${ }^{30}$

Ampliando o número de escolas técnicas, a educação profissional criaria um "espírito" ligado às ações empreendedoras tão fundamentais ao país. A instrumentalização da mão-de-obra não apenas era parte integrante e indissociável do esforço de montar sofisticados complexos industriais. Tornava-se imperiosa a elevação da vida educacional de um povo para que este atingisse a verdadeira ascensão:

(...) Não se trata apenas de adquirir, montar e operar instalações industriais. A ascensão dos povos só é verdadeira, segura e duradoura quando se faz em setor mais delicado que o material, isto é, quando toda a Nação se educa, instruindo-se e adquirindo tal experiência, que ela se torna de fato consciente do desenvolvimento que se realiza. Não é só do equipamento econômico que se trata, mas de equipamento espiritual. ${ }^{31}$

A realização de um grande plano nacional de educação técnica para trabalhadores e membros dirigentes determinava a remodelação dos padrões vigentes no sistema educacional brasileiro, cuja matriz européia necessitava ser urgentemente repensada ou o país estaria condenado a ter um ensino não "ajustado às realidades":

De outro lado, a extraordinária e secular influência que a civilização européia exerceu sobre a América Latina induziu à predominante adoção do ensino de natureza acadêmica entre nós. Tivemos a pretensão de assimilar uma atitude mental e uma técnica pedagógica que estavam em desacordo com os padrões sociais e econômicos do nosso estágio histórico próprio (...) Era, contudo, inadequada como sistema de âmbito nacional a países de feição predominantemente agrária, como o nosso. ${ }^{32}$ 
Ao relacionar o desenvolvimento da nação à expansão contínua dos seus aparelhos escolares - especialmente os técnicos - Macedo Soares definiu algumas linhas para o modelo educacional que considerava ideal para um país como o Brasil, englobando todas as faixas etárias e níveis de formação:

O problema não consiste só em alfabetizar. Mas em proporcionar aos adolescentes (entre 13 e 20 anos ) uma formação profissional suficiente para torná-los cidadãos prestantes, ou suficientemente preparados para receber o ensino universitário. E dar aos que adquirem a necessária base 0 ensino superior ( universitário ) que forma os quadros de cúpula da nação. A qualidade do ensino deve ser cuidada, a fim de que não se caia no erro de formar uma nação primária e mal preparada para enfrentar o impacto do desenvolvimento científico e tecnológico.

A educação deve dar aos jovens uma noção mais perfeita dos seus objetivos e combater o 'diplomismo' (...) Assim para ocupar postos públicos e ter acesso à prática das profissões, é mais importante ter um 'certificado' do que conhecimentos seguros.

A educação, num país na posição do Brasil, deverá ser conduzida de modo que todos recebam um mínimo de conhecimentos ( leitura, contas, escrita ) e, acima disso, por seleção adequada, ir caminhando para o vértice da pirâmide, de forma que ensino primário, ensino médio ( profissional e pré-colegial ), ensino colegial ( profissional e básico para as universidades ) e ensino universitário abranjam um número elevado de jovens, preparando-os para as carreiras que fazem o progresso do país.

(...) Os três grandes objetivos de um Estado Moderno:

a) Alfabetizar a maior percentagem da população;

b) Formar quadros médios suficientemente instruídos, inclusive mão-de-obra técnica; 
c) Preparar quadros superiores para as grandes tarefas da administração pública e privada, ensino e pesquisa tecnológica e científica.

Dentro de três ou quatro lustros, o sistema acima colocaria o Brasil em posição ímpar entre as nações do mundo.

Todas essas recomendações deveriam ser executadas para que o Brasil progredisse em um contexto de radicalização da competição econômica e do avanço, em escalas cada vez maiores, das conquistas tecnológicas e científicas. A educação, mais do que preparar homens para o trabalho, deveria formar uma mentalidade, uma cultura necessária ao engrandecimento nacional. Para Macedo Soares, essa “cultura” era formada por "nível médio de instrução; adiantamento científico e tecnológico; formação filosófica e convicção religiosa; mentalidade da classe dominante". Em um outro contexto, em que discutia os recursos que os empresários deveriam destinar à formação e especialização técnica dos seus trabalhadores, Macedo Soares fazia uma clara distinção entre o estudante técnico de nível médio e o aluno de um curso superior de engenharia, a este último sendo destinadas funções de direção e domínio da força de trabalho:

O aluno de uma escola técnica tem conhecimentos suficientes para interessar-se por um estágio e compreender a maquinaria de uma indústria. O mesmo não acontece com o estudante de uma escola de engenharia (...) Ele poderá compreender a organização, conhecer as peças de equipamentos individualmente, sentir o esforço dos trabalhadores no cumprimento de suas tarefas, tomar conhecimento de problemas disciplinares e das condições de vida do pessoal que, no futuro, ficarão a seu cargo.

As idéias e sugestões de Macedo Soares são relevantes para a compreensão de como a modernização pretendida pela fração industrial da burguesia brasileira pensava a formação escolar. A alfabetização deveria atingir níveis cada vez maiores da população, produzindo um contingente maior de indivíduos com formação média, preferencialmente técnica. Contudo, apenas uma elite deveria conduzir o desenvolvimento científico e tecnológico do país - além da própria administração pública. É importante ressaltar que ao longo de toda sua trajetória intelectual, Macedo Soares 
afirmou sistematicamente estas idéias, defendendo veementemente a noção de que o desenvolvimento nacional deveria ser conduzido por uns poucos indivíduos dotados de formação amplamente científica, devendo, ainda, ocupar postos de docência em diversos aparelhos escolares com o intuito de difundir - de forma cuidadosamente controlada - esta cultura técnicocientífica. Não é estranho, portanto, que o próprio Macedo Soares tenha sido professor de prestigiosas escolas de engenharia, como o Instituto Militar de Engenharia e o Instituto Tecnológico da Aeronáutica.

\section{CONSIDERAÇÕES FINAIS}

O que foi chamado aqui de modernização brasileira comportou, a partir dos anos 20, um conjunto de transformações na ordem político-econômica em que se destacaram a crescente centralização dos aparelhos estatais decisórios e o aumento dos níveis de industrialização. Paralelamente, a fração burguesa que mais se beneficiou com estas mudanças articulou um discurso ideológico com a pretensão de tornar nacionais seus interesses específicos de classe. A construção de um consenso hegemônico era essencial para que a direção do processo coubesse à burguesia industrial em ascensão, visto que esta procurava recompor o poder com as frações das oligarquias rurais e realizava concessões às camadas subalternas da sociedade.

A trajetória de Macedo Soares é decisiva para a compreensão dos caminhos da modernização industrial brasileira, seus mecanismos de dominação, a repressão à força de trabalho - tutelada pela legislação estatal trabalhista -, a construção de um discurso hegemônico, etc. É ainda significante para a elucidação dos meandros pelos quais as demandas surgidas pelos aparelhos privados da burguesia industrial inscreviam-se na ossatura material do Estado, uma vez que este personagem exerceu destacada atuação tanto no âmbito da sociedade civil quanto no da sociedade política, entendendo estes conceitos numa acepção gramsciana.

As práticas e representações envolvidas na modernização brasileira destacaram a relevância de determinados agentes para a compreensão do processo como um todo. Ao lado da burguesia industrial, os engenheiros se destacaram por sua personificação da ciência e da tecnologia e por uma 
intervenção direta nos mecanismos de regulação da ordem econômicosocial. Atribuíam a si a função de dirigentes do movimento de expansão do capital, revelando uma vocação modernizante, ao mesmo tempo em que flertavam com os novos métodos de racionalização do trabalho a partir do reforço do controle sobre a mão-de-obra. Ao lado dos industriais e de um Estado que se ampliava para incorporar novas demandas produzidas na sociedade civil, portavam as credenciais indispensáveis para a correção dos rumos da nação, superando o atraso histórico a que estivemos submetidos pelo colonialismo ibérico.

Pensar a posição e a produção intelectual de Macedo Soares neste processo é elevá-lo à condição de ideólogo de um projeto modernizador autoritário-conservador que resultou da crise de hegemonia dos anos 30. Nestas circunstâncias, redefiniram-se não apenas as modalidades de acumulação e as funções do Estado, como os próprios discursos que procuravam situar a trajetória histórica do Brasil, visto como uma nação marcada pelo peso da ocupação ibérica e pelo persistente atraso econômico e político. Essa condição de defasagem deveria ser tomada como um momento, um estágio em direção ao progresso e ao maior bem-estar material possível.

Por fim, este artigo procurou situar o discurso e os indivíduos como partes constitutivas da realidade social e do processo de reprodução da vida material, o que significa também reportá-los à dinâmica das classes sociais e de seus conflitos. Aqui a produção de idéias e visões de mundo apresenta-se como um movimento político que busca a concretização de determinadas aspirações de uma dada classe em confronto com outras. Para isso, pressupõe-se que se desenvolva uma certa identidade de classe, na qual o discurso surge como um dos mais poderosos instrumentos.

\section{NOTAS}

1 ALONSO, Ângela. Idéias em movimento: a geração 1870 na crise do Brasil-Império. São Paulo: Paz e Terra, 2002. Segundo a autora, a geração de intelectuais brasileiros da década de 1870 caracterizou-se pelo ecletismo teórico, esposando correntes que iam do positivismo ao liberalismo, passando pelo evolucionismo de Spencer e pelo cientificismo. Faziam parte desta geração autores das mais diversas procedências sociais e intelectuais, como Joaquim Nabuco, Silvio Romero, André Rebouças, Silva Jardim, Miguel Lemos, Quintino Bocaiúva, entre outros. Os pontos de contato 
entre esses homens eram a crítica ao sistema monárquico e um pouco preciso projeto reformista, convergindo ainda para uma dedicada atuação política.

2 GRAMSCI, Antonio. Cadernos do Cárcere. Organização de Carlos Nélson Coutinho. Rio de Janeiro Civilização Brasileira, 2000.

3 A clássica referência na historiografia a respeito do papel dos engenheiros é o trabalho de Lili Katsuco Kawamura. Ver KAWAMURA, Lili Katsuco. Engenheiro: trabalho e ideologia. São Paulo, Ática, 1991.

4 ANTONACCI, Maria Antonieta Martinez. A vitória da razão? O IDORT e a Sociedade Paulista. São Paulo, Editora Marco Zero, 1993, p.13.

5 VIANNA, Luiz Werneck. O moderno na política brasileira. Presença. n.5. São Paulo, 1985, p.37.

6 MAZA, Fábio. Intelectuais, classes e Estado no Brasil. Trabalho apresentado ao I Simpósio "Estado Brasileiro: Agências e Agentes”. Niterói, 2004, p. 5 ( mimeo ).

7 HABERMAS, Jürgen. Técnica e ciência enquanto ideologia. Os Pensadores. São Paulo: Abril, 1983, p.303.

8 Idem, p.304.

9 MAZA, Fábio. O idealismo prático de Roberto Simonsen: ciência, tecnologia e indústria na construção da nação. São Paulo: Instituto Roberto Simonsen, 2004, p.78.

10 GRIGNON, Claude. L'ordre dês choses: les fonctions sociales de l'enseigment technique. Paris: Les Éditions de Minuit, 1971, p.13.

11 LUKÁCS, Gyorgy. Tecnologia e relações sociais. In: BUKARIN, VV.AA. Teoria marxista. Belo Horizonte: Oficina do Livro, 1989, p.45.

12 VARGAS, Milton. Para uma filosofia da tecnologia. São Paulo: Alfa-Ômega, 1994, p.172.

13 Idem, p. 179.

14 Idem, p. 182.

15 KAWAMURA, Lili Katsuco. Op.cit., p.50.

16 O conceito de sociometabolismo do capital está em MÉSZÁROS, István. Para além do capital: rumo a uma teoria da transição. Campinas: Editora da UNICAMP. São Paulo: Boitempo Editorial, 2002. Ver Introdução e Capítulo 1.

17 MARX, Karl. O Capital. Tradução de Reginaldo Sant'Anna.18.ed. Livro I, volume I. Rio de Janeiro: Civilização Brasileira, 2001, p.384.

18 ABREU, Marcelo de Paiva. O Brasil e a economia mundial: 1930-1945. Rio de Janeiro: Civilização Brasileira, 1999; BIELSCHOWSKY, Ricardo. Pensamento econômico brasileiro: o ciclo ideológico do desenvolvimentismo. Rio de Janeiro: Contraponto, 2000; CORSI, Francisco Luiz. Estado Novo: política externa e projeto nacional. São Paulo: UNESP/FAPESP, 2000; DINIZ, Eli. Empresário, estado e capitalismo no Brasil. Rio de Janeiro: Paz e Terra, 1978; DRAIBE, Sônia. Rumos e metamorfoses: Estado e industrialização no Brasil: 1930/1960. Rio de Janeiro: Paz e Terra, 1985; FONSECA, Pedro Cézar Dutra da. Vargas: capitalismo em construção. São Paulo: Brasiliense, 1989; LEOPOLDI, Maria Antonieta P. Política e interesses na industrialização brasileira: as associações industriais, a política econômica e o Estado. São Paulo: Paz e Terra, 2000; LODI, Euvaldo. Conferências e discursos. Rio de Janeiro: CNI, 1954; MELLO, João Manuel Cardoso. O capitalismo tardio. São Paulo: Brasiliense, 1988; SIMONSEN, Roberto. Ensaios sociais, políticos e econômicos. São Paulo: Editora FIESP, 1943; SUZINGAN, Wilson. Indústria brasileira: origem e desenvolvimento. São Paulo: Hucitec; Campinas: UNICAMP, 2000; WIRTH, John. A política de desenvolvimento na era de Vargas. Rio de Janeiro: Fundação Getúlio Vargas, 1973.

19 PINTO, Sérgio Murilo. A doutrina Góis: síntese do pensamento militar no Estado Novo. In: PANDOLFI, Dulce (org). Repensando o Estado Novo. Rio de Janeiro: FGV, 1991, p.291. 
20 SOARES, Edmundo. A formação técnica do brasileiro. Carta Mensal. n.293, v.25. Rio de Janeiro, ago/1979, p.08.

21 Idem, ibidem.

22 Idem, ibidem.

23 Idem, ibidem.

24 Idem, ibidem.

25 SOARES, Edmundo de Macedo. Aula inaugural dos cursos da Faculdade de Engenharia da Universidade do Estado da Guanabara. CPDOC. Arquivo Macedo Soares. EMS.E. 1966.03.04.

26 SOARES, Edmundo de Macedo. O Brasil no mundo atual. O engenheiro no Brasil Aula inaugural do curso do Instituto Tecnológico da Aeronáutica. CPDOC. Arquivo Macedo Soares. EMS.E. 1970.03.02.

27 SOARES, Edmundo de Macedo. Tecnologia e desenvolvimento. Carta Mensal. n.229, v.20. Rio de Janeiro, abril/1974, p.38-39.

28 SOARES, Edmundo de Macedo. História da cultura brasileira: reflexos da II Guerra Mundial. CPDOC. Arquivo Macedo Soares. EMS. E. 000.00.00/11.

29 SOARES, Edmundo de Macedo. Os problemas da indústria. CPDOC. Arquivo Macedo Soares. EMS. E. 0000.00.00/24.

30 SOARES, Edmundo de Macedo. O momento e a missão da indústria. Discurso de posse do General Edmundo de Macedo Soares na presidência da Confederação Nacional da Indústria, em 07/12/1964. Rio de Janeiro: Biblioteca Nacional.

31 SOARES, Edmundo de Macedo. Discurso pronunciado na abertura do Congresso Brasileiro para Reformas de Base em São Bernardo do Campo, São Paulo. EMS. E. 1963.01.18.

32 Idem, ibidem.

33 Idem, ibidem.

34 SOARES, Edmundo de Macedo. Aula inaugural dos cursos da Faculdade de Engenharia da Universidade do Estado da Guanabara. CPDOC. Arquivo Macedo Soares. EMS.E. 1966.03.04.

35 SOARES, Edmundo de Macedo. Importância das relações entre empresário e o estudante no desenvolvimento econômico e social do país. Rio de Janeiro: Biblioteca Nacional. Documento de 08 de fevereiro de 1965 .

\section{REFERÊNCIAS}

ABREU, Marcelo de Paiva. O Brasil e a economia mundial: 1930-1945. Rio de Janeiro: Civilização Brasileira, 1999.

ALONSO, Ângela. Idéias em movimento: a geração de 1870 e a crise do BrasilImpério. São Paulo: Paz e Terra, 2002.

AVELAR, Alexandre de Sá. A modernização brasileira no pensamento do General Edmundo de Macedo Soares ( 1937-1987). Tese de Doutorado. Niterói: Programa de Pós-Graduação em História/Universidade Federal Fluminense, 2006.

. A trajetória do Major Edmundo de Macedo Soares e a formação de um pensamento técnico-industrial no Exército durante o Primeiro Governo Vargas. 
Comunicação apresentada no II Encontro de Pós-Graduação em Historia Econômica. Niterói: UFF, 2004.

.Um construtor nacional: o General Edmundo de Macedo Soares e a montagem da grande siderurgia no Brasil. Métis: história \& cultura. Revista de História da Universidade de Caxias do Sull. n.2, v.2. Caxias do Sul: UCS, 2003, p.173-196.

ANTONACCI, Maria Antonieta Martinez. A vitória da razão? O IDORT e a sociedade paulista. São Paulo, Editora Marco Zero, 1993.

BIELSCHOWSKY, Ricardo. Pensamento econômico brasileiro: o ciclo ideológico do desenvolvimentismo. Rio de Janeiro: Contraponto, 2000.

CORSI, Francisco Luiz. Estado Novo: política externa e projeto nacional. São Paulo: Editora da UNESP/FAPESP, 2000.

DINIZ, Eli. Empresário, estado e capitalismo no Brasil. Rio de Janeiro: Paz e Terra, 1978.

DRAIBE, Sônia. Rumos e metamorfoses: Estado e industrialização no Brasil19301960. Rio de Janeiro: Paz e Terra, 1985.

FONSECA, Pedro Cézar Dutra da. Vargas: capitalismo em construção. São Paulo: Brasiliense, 1989.

GORZ, André. Divisão do trabalho, hierarquia e luta de classes. In: . Divisão social do trabalho, ciência, técnica e modo de produção capitalista. Porto: Public, 1974.

GRAMSCI, Antônio. Cadernos do Cárcere. Organização de Carlos Nélson Coutinho. Rio de Janeiro: Civilização Brasileira, 2000.

GRIGNON, Claude. Lordre dês choses: les fonctions sociales de l'enseigment technique. Paris: Les Éditions de Minuit, 1971.

HABERMAS, Jürgen. Técnica e ciência enquanto ideologia. Os Pensadores. São Paulo: Abril, 1983.

KAWAMURA, Lili Katsuco. Engenheiro: trabalho e ideologia. São Paulo, Ática, 1991. 
LEOPOLDI, Maria Antonieta P. Política e interesses na industrialização brasileira: as associações industriais, a política econômica e o Estado. São Paulo: Paz e Terra, 2000.

LODI, Euvaldo. Conferências e discursos. Rio de Janeiro: CNI, 1954.

LUKÁCS, Gyorgy. Tecnologia e relações sociais. In: BUKARIN, VVAA. Teoria marxista. Belo Horizonte: Oficina do Livro, 1989.

MARX, Karl. O Capital. Tradução de Reginaldo Sant'Anna.18.ed. Livro I, volume I. Rio de Janeiro: Civilização Brasileira, 2001.

MAZA, Fábio. Intelectuais, classes e Estado no Brasil. Trabalho apresentado ao I Simpósio “Estado Brasileiro: Agências e Agentes”. Niterói, 2004. ( mimeo ).

. O idealismo prático de Roberto Simonsen: ciência, tecnologia e indústria na construção da nação. São Paulo: Instituto Roberto Simonsen, 2004.

MELLO, João Manuel Cardoso. O capitalismo tardio. São Paulo: Brasiliense, 1988.

MÉSZÁROS, István. Para além do capital: rumo a uma teoria da transição. Campinas: UNICAMP. São Paulo: Boitempo Editorial, 2002.

PINTO, Sérgio Murilo. A doutrina Góis: síntese do pensamento militar no Estado Novo. In: PANDOLFI, Dulce (org). Repensando o Estado Novo. Rio de Janeiro: FGV, 1991.

SIMONSEN, Roberto. Ensaios sociais, políticos e econômicos. São Paulo: Editora FIESP, 1943.

SUZINGAN, Wilson. Indústria brasileira: origem e desenvolvimento. São Paulo: Hucitec; Campinas: Editora da UNICAMP, 2000.

VARGAS, Milton. Para uma fillosofia da tecnologia. São Paulo: Alfa-Ômega, 1994.

VIANNA, Luiz Werneck. O moderno na política brasileira. Presença. n.5. São Paulo, 1985 .

WIRTH, John. A política de desenvolvimento na era de Vargas. Rio de Janeiro: Fundação Getúlio Vargas, 1973. 
educação técnica e egenharia no...

\section{FONTES PRIMÁRIAS PESQUISADAS}

Biblioteca Nacional - Documentos sobre Edmundo de Macedo Soares.

Centro de Pesquisa e Documentação de História Contemporânea do Brasil (CPDOC) Fundação Getúlio Vargas-RJ. Arquivo Macedo Soares.

Confederação Nacional do Comércio - Revista Carta Mensal. 